\title{
Fat Re-Grafting in Facial Asymmetry: A 2-Case Report
}

\author{
Ahmed Abdel Hady El Danaf ${ }^{*}$, Ahmad Abdelmaksoud Rabie ${ }^{2}$ \\ ${ }^{1}$ Plastic Surgery Department, Mataria Teaching Hospital, Cairo, Egypt \\ ${ }^{2}$ Dermatology Department, National Research Centre, Cairo, Egypt \\ Email: *ahmed_el_danaf@hotmail.com
}

Received 15 December 2015; accepted 16 January 2016; published 19 January 2016

Copyright (C) 2016 by authors and Scientific Research Publishing Inc.

This work is licensed under the Creative Commons Attribution International License (CC BY).

http://creativecommons.org/licenses/by/4.0/

c) (i) Open Access

\begin{abstract}
Fat redistribution through recycling of previously grafted fat hasn't been reported. Two facial asymmetry patients are presented with history of fat grafting to the mandibular angle areas. Collected fat from these formerly fat grafted zones and swollen on subsequent extra body weight gain has been re-grafted in the temporal regions for contour enhancement and has retained volume as photographically documented up to 30 months.
\end{abstract}

\section{Keywords}

Fatre-Grafting, Fat Transfer, Liposuction Dry Technique, Facial Asymmetry, Hemifacial Microsomia

\section{Introduction}

Fat grafting to the face has become one of the most common and safe procedures that help both facial contouring and rejuvenation. Bulging of facial areas previously grafted with fat after body weight gain is a gradually more existing clinical hitch. This paper intends to present a key through liposuction of areas formerly fat-grafted in the face and re-cycling the extracted fat cells as fillers in other facial areas, an application that has not been addressed in literature.

\section{Presentation}

Two patients with the developmental First and Second Brancheal Arch Syndrome (Hemifacial Microsomia) presented mainly for facial contouring. Their deficient mandibular angle areas were treated with fat grafting.

${ }^{*}$ Corresponding author. 
Grafts few years later showed enlargement on weight gain. The over-stuffed area was treated with syringe dry liposuction and the extracted fat-after taking patients consent-was re-cycled in the temporal zones for cosmetic reason. Fat re-grafting was successful without complications, new face outlines were maintained and patients showed satisfaction.

\subsection{Case 1}

A 22-year old female patient presented with bilateral mild maxillo-mandibular developmental hypoplasia which was more intense on the left side. She was primarily treated with fat grafting to the mandibular angle and preauricular regions, $20 \mathrm{ml}$ on the left side and $30 \mathrm{ml}$ on the right. This procedure was associated with anterior maxillary tilting (removing the upper left premolar) setback osteotomy. Six months later a combined rhinoplasty and advancement genioplasty was carried out. Four years later, when her body weight had markedly increased, the patient came complaining from recent enlargement of her fat-recipient mandibular angle zones. She accepted to get liposuction of these areas and to make use of the extracted fat cells for facial temporal region augmentation. Liposuction without prior infiltration was carried out using 20 cc syringes and $2 \mathrm{~mm}$ blunt cannula. The easily extracted soft fat lobules stained with frank blood measured $7 \mathrm{ml}$ from the right mandibular angle and $4 \mathrm{ml}$ from the left. Five ml collected fat was directly re-injected in her depressed temporal area on each side. The re-grafted fat in the new hosting temporal sieges has retained volume as followed up to 30 months (Figure 1).

\subsection{Case 2}

A 25-year old patient presented with right hemifacial microsomia and chose correction with fat grafting rather than undergoing any facial osteotomy surgery. Centrifuged $80 \mathrm{ml}$ trunk fat was grafted to the right facial lower two thirds: $35 \mathrm{ml}$ to the mandibular angle area injected supra-periosteal deep to the masseter muscle via an intra-oral approach and $45 \mathrm{ml}$ injected subcutaneous through a tiny skin port below ear-lobule. The grafted areas 8 years later got overstuffed on recent body extra weight gain. Fifteen ml fat was suctioned with syringe dry technique from the mandibular right side and was re-cycled to the right temporal area and both lips. Two months follow up consultation revealed maintained volume of these areas (Figure 2).

\section{Discussion}

Changes in adipose tissue volume are principally related to cell size and its intra-cellular lipid content. While the number of fat cells was generally assumed to be stable after full physical adolescent growth has been achieved [1], hyperplastic obesity has been proven manifestly as body fat levels exceed $40 \mathrm{~kg}$ [2]. On weight loss, fat cells shrink and may even dedifferentiate and on weight gain they redifferentiate and increase in volume [3]. Although transferred cells are not expected to regenerate, new adipose cells are thought to be developed by a population of stem cells, residing in the stromal vascular fraction of lipoaspirate tissue [4]-[6]. On weight gain,
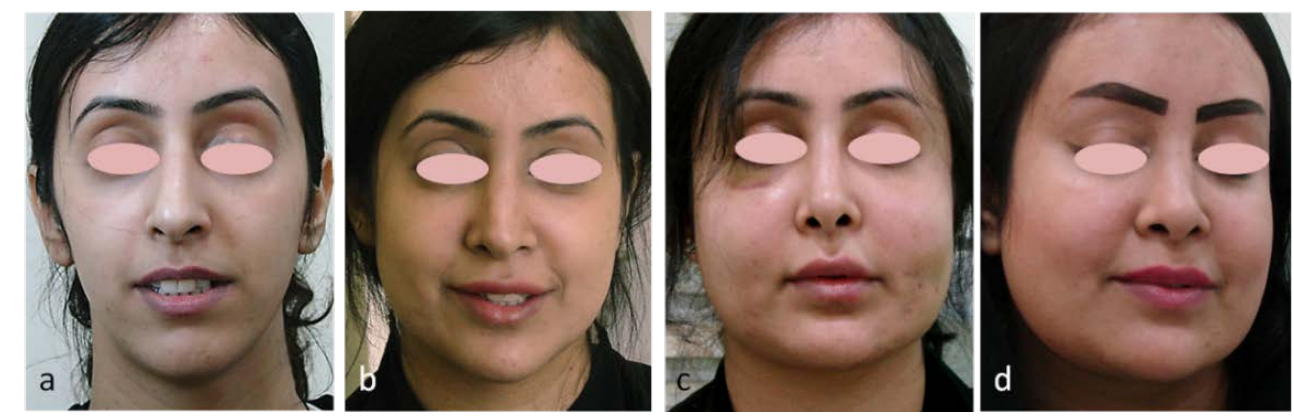

Figure 1. (a) Mild bilateral asymmetric facial microsomia; (b) Three years after fat transfer to the mandibular angle regions associated with anterior maxillary osteotomy and shortly afterward followed with rhino-and genio-plasty; (c) One year later when bodyweight started to increase, just prior to fat re-grafting from the mandibular to the temporal areas and (d) Retained temporal area contour 30 months after the fat re-distribution (The showing recurrent mandibular angle bulge was due to further body weight gain). 

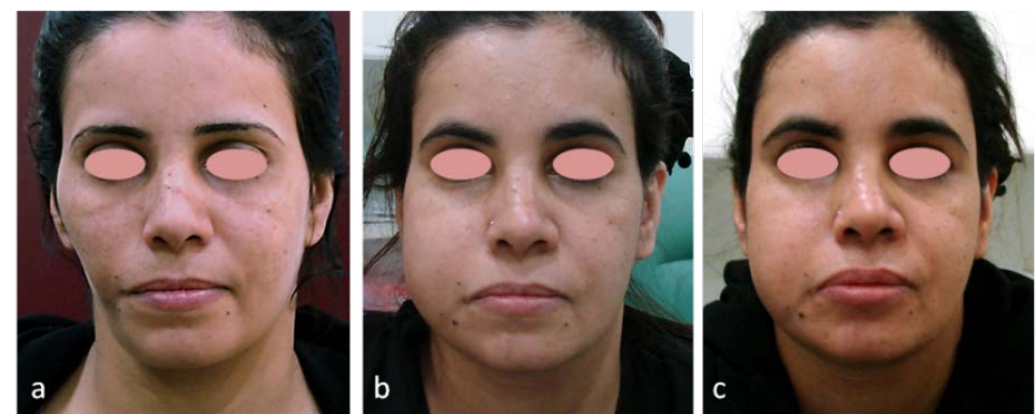

\begin{abstract}
Figure 2. (a) Right hemifacial microsomia; (b) Eight years after $80 \mathrm{ml}$ fat transfer to the right lower 2/3 of the face and subsequent obesity and (c) Two months after re-grafting of $15 \mathrm{ml}$ fat harvested from the right mandibular angle area to the right temporal area and lips (The left temporal area was grafted with fresh fat harvested from the abdominal wall).
\end{abstract}

fat cells in the common subcutaneous donor sites (trunk, thighs and arms) are usually more susceptible to hypertrophy and/or hyperplasia than those originally residing facial recipient areas. Fat graft regularly increases in size with subsequent overall weight gain. Doesn't grafted adipocyte retain memory to match its original donor site cells volume changes in response to weight loss or gain, rather than to get in compliance with the recipient in-house cells doctrine? Transplanted fat cells resembling transplanted hair follicles seem to conserve genetic donor-site codes and hence its volume regulations follow eventual changes in the donor site cells. Studying fat grafted areas with MRI-imaging and histological examination would have conclusively proven fat hypertrophy, hyperplasia and any increase in extracellular tissue components. Facial fat grafting in orthognathic surgery cases has been over the past few years [7]-[12] an easier alternative or additive armamentarium to the heavier osteotomy operations particularly when patient occlusion is acceptable or correctable in dental clinics.

Structural fat grafting in the two presented cases entails liposuction in facial areas where lipofilling has been performed previously and followed by re-processing for lipofilling in other facial areas. The dry liposuction technique was used to help precise assessment of the bulges reduction. The quality of the dry fat aspirate wouldn't improve through a centrifuge process.

\title{
4. Conclusion
}

In conclusion, extraction of previously grafted fat and re-cycling this extracted fat in other areas may constitute a novelty which offers a new acceptable relevance to the existing clinical problem "enlargement of previously fat grafted facial areas when patient becomes obese”.

\section{References}

[1] Smahel, J. (1986) Adipose Tissue in Plastic Surgery. Annals of Plastic Surgery, 16, 444-453. http://dx.doi.org/10.1097/00000637-198605000-00012

[2] Chalekson, C., Jorge, I., de la Torre, et al. (2011) Liposuction Techniques Treatment \& Management. http://emedicine.medscape.com/article/1272642-overview\#a0104

[3] Ashok Tholpady, A., Al Aly, et al. (2011) Facial Fat Grafting. http://emedicine.medscape.com/article/1283020-treatment\#a1133

[4] Tholpady, S.S., Llull, R., Ogle, R.C., et al. (2006) Adipose Tissue: Stem Cells and Beyond. Clinics in Plastic Surgery, 33, 55-62. http://dx.doi.org/10.1016/j.cps.2005.08.004

[5] Zuk, P.A., Zhu, M., Ashjian, P., et al. (2002) Human Adipose Tissue Is a Source of Multipotent Stem Cells. Molecular Biology of the Cell, 13, 4279-4295. http://dx.doi.org/10.1091/mbc.E02-02-0105

[6] Brzoska, M., Geiger, H., Gauer, S., et al. (2005) Epithelial Differentiation of Human Adipose Tissue-Derived Adult Stem Cells. Biochemical and Biophysical Research Communications, 330, 142-150. http://dx.doi.org/10.1016/j.bbrc.2005.02.141

[7] Pasquale, P., Gaetano, M., Giovanni, D.O., Luigi, C. and Gilberto, S. (2015) Autologous Fat Grafting in Facial Volumetricrestoration. Journal of Craniofacial Surgery, 26, 756-759. http://dx.doi.org/10.1097/SCS.0000000000001663

[8] Agostini, T., Spinelli, G., Marino, G., et al. (2014) Esthetic Restoration in Progressive Hemifacial Atrophy (Romberg 
Disease): Structural Fat Grafting versus Local/Freeflaps. Journal of Craniofacial Surgery, 25, 783-787. http://dx.doi.org/10.1097/SCS.0000000000000831

[9] Guijarro-Martínez, R., Miragall Alba, L., Marqués Mateo, M., Puche Torres, M. and Pascual Gil, J.V. (2011) Autologous Fat Transfer to the Cranio-Maxillofacial Region: Updates and Controversies. Journal of Cranio-Maxillofacial Surgery, 39, 359-363. http://dx.doi.org/10.1016/j.jcms.2010.07.004

[10] Mojallal, A.L., Shipkov, C., Braye, F., et al. (2009) Influence of the Recipient Site on the Outcomes of Fat Grafting in Facial Reconstructive Surgery. Plastic and Reconstructive Surgery, 124, 471-483. http://dx.doi.org/10.1097/PRS.0b013e3181af023a

[11] El Danaf, A. (2009) Fat Transfer to the Face in Maxillofacial Osteotomy Patients. 45th Congress of the "Societe Francaise de Stomatologie et Chururgie Maxillo-Faciale”, Palais des Congres, 10-12 September 2009.

[12] Xie, Y., Li, Q., Zheng, D., Lei, H. and Pu, L.L. (2007) Correction of Hemifacial Atrophy with Autologous Fat Transplantation. Annals of Plastic Surgery, 59, 645-653. 